\title{
MÚLTIPLOS COMPROMETIMENTOS NO TRABALHO: UM ESTUDO ENTRE TRABALHADORES DE ORGANIZAÇÕES AGRÍCOLAS DO POLO DE FRUTICULTURA IRRIGADA DE JUAZEIRO/PETROLINA
}

\author{
Multiple commitments at work: the bonds of workers \\ from agricultural organizations
}

Envio 27.04.09 / Aceite 13.10.09

\author{
Fabíola Marinho Costa ${ }^{1}$ \\ Antonio Virgílio Bittencourt Bastos ${ }^{2}$
}

\section{Resumo}

Os estudos de comprometimento, dentro de uma perspectiva multidimensional, investigam como os indivíduos articulam seus diversos focos de compromisso e os diferentes processos psicológicos que embasam seus vínculos. Apoiado nesta perspectiva, o presente estudo toma como campo de análise organizações agroindustriais do polo Juazeiro/Petrolina, pelo que estas representam de inovação tecnológica e organizacional no contexto agrário nordestino, e descreve os níveis de comprometimento dos trabalhadores com o trabalho, com a organização empregadora e a natureza afetiva e instrumental desse vínculo com a organização. Trata-se de um estudo extensivo de corte transversal, em 32 organizações, envolvendo uma amostra de 919 trabalhadores. Os dados foram coletados por meio de entrevistas estruturadas, compostas por escalas Likert de sete pontos, realizando-se, posteriormente, análises descritivas e análises de variância com o auxílio do programa SPSS. Foram encontrados elevados níveis de

\footnotetext{
1 Professora Assistente da Universidade Federal do Recôncavo Baiano (UFRB), Doutoranda em Psicologia pela Universidade Federa da Bahia (UFBA). E-mail: fabiolamcosta@gmail.com

${ }^{2}$ Prof. Titular do Departamento de Psicologia e dos Programas de Pós-Graduação em Psicologia e em Administração da UFBA. E-mail: virgilio@ufba.br
} 
comprometimento entre os dois focos (6,42 - trabalho e 5,83 - organização) e as duas bases (5,30 - afetiva e 5,22 - instrumental) estudadas. Tais achados devem ser interpretados à luz das relações de trabalho, dos padrões culturais que embasam a relação dos indivíduos com seu trabalho e seus empregadores e do contexto socioeconômico da região.

Palavras-chave: Comprometimento Organizacional; Comprometimento com o Trabalho; Trabalhadores de Organizações Agrícolas.

\begin{abstract}
Commitment studies, from a multidimensional perspective, investigate how individuals articulate their many focuses of commitment and the different psychological processes which found these bonds. Supported by this perspective, the present study takes as a field of analysis agroindustrial organizations at the Juazeiro/Petrolina pole, for the technological and organizational innovations they represent in northeastern agricultural context, and describes the levels of commitment of the employees to work, to the employer organization and the affective and instrumental nature of this bond with the organization. This is a cross-sectional extensive study, in 32 agricultural organizations, involving a 919 workers' sample. The data were collected with structured interviews, constituted by seven-point-Likert scales; later, descriptive and variance analyses through the SPSS program were made. High levels of commitment were found between the two focuses (6,42 - work and 5,83 - organization) and the two bases (5,30 - affective and 5,22 - instrumental) studied. Such findings should be interpreted in the light of work relationships, of the cultural patterns which support the relationship of individuals with their work and their employers, and also of the socioeconomic context of the area.
\end{abstract}

Keywords: Organizational Commitment; Commitment to Work; Agricultural Organizations; Agricultural Organizations'Workers.

\title{
1 Introdução
}

Existe uma sólida tradição de pesquisa na área do comprometimento, que se tornou, sobretudo nos últimos dez anos, um dos tópicos de pesquisa mais intensamente estudado no campo da pesquisa micro-organizacional, tanto no exterior quanto no Brasil. No entanto, as agendas de pesquisa, estabelecidas por diversos autores considerados clássicos nesse campo de estudo, apontam lacunas e novos desafios para este domínio de pesquisa (BASTOS, 1994, 1995; MEDEIROS et al., 2002). Dentre os possíveis avanços na área, pode-se incluir a incorporação de contextos organizacionais e segmentos de trabalhadores ignorados ou muito esporadicamente estudados na pesquisa acadêmica em comportamento organizacional. Até então, os estudos sobre comprometimento foram conduzidos em empresas industriais e de serviço, quase sempre localizadas em grandes centros ou em suas áreas metropolitanas.

O presente trabalho incorpora aos estudos acerca do comprometimento a investigação de segmentos da agricultura moderna e agroindústria, analisando um contexto extremamente importante para a economia dos Estados da Bahia e de Pernambuco. As organizações agrícolas do polo Juazeiro/Petrolina foram o campo de análise deste estudo, tendo como foco principal um segmento de trabalhadores que vivencia uma agricultura moderna em tecnologias físicas e organizacionais. Buscou-se caracterizar o trabalhador em termos de seus vínculos com o trabalho e a organização, investigando como estes se configuram. Foi explorado, portanto, o complexo vértice que une indivíduos, trabalho e organizações, utilizando-se o comprometimento como referencial teórico para a investigação.

Articula-se, portanto, um tópico clássico e ao mesmo tempo atual de pesquisa a um contexto no qual ainda não fora estudado e cuja dinâmica tecnológica e organizacional 
tem impacto profundo em uma região desafiada a superar seus fracos indicadores sociais e econômicos. Inserido em um projeto de pesquisa de mais amplo escopo, esta comunicação detém-se na caracterização de múltiplos comprometimentos no trabalho em uma amostra de trabalhadores de empresas agrícolas do Baixo Médio São Francisco, no nordeste brasileiro.

\subsection{Comprometimento no trabalho}

Vários conceitos foram construídos por estudiosos para representar uma série de reações dos indivíduos dirigidas ao trabalho executado e à organização empregadora, objetos intimamente relacionados entre si, porém capazes de desencadear percepções, afetos, intenções e ações diferenciados nos trabalhadores (SIQUEIRA e GOMIDE JÚNIOR, 2004). Dentre estes, surgiu o conceito psicossocial de 'comprometimento'.

Atualmente, o comprometimento no trabalho tem recebido grande atenção dos pesquisadores, sendo considerado um importante conceito para a compreensão de como se articulam os vínculos das pessoas com seus trabalhos e empresas empregadoras. $\mathrm{O}$ comprometimento no trabalho vem sendo concebido como um requisito de bom desempenho, relações interpessoais adequadas, eficiência e eficácia individuais e organizacionais (BASTOS e COSTA, 2000).

O comprometimento tem sido definido como uma atitude que reflete sentimentos, como apego, identificação ou lealdade, com o objeto de compromisso (MORROW, 1993). Nas organizações, os indivíduos possuem uma série de compromissos - com a organização, o trabalho, o grupo de trabalho, a ocupação - que afetam seus comportamentos no trabalho, o que caracteriza uma abordagem multidimensional do fenômeno e conduz à pesquisa de como esses múltiplos vínculos são articulados (COHEN, 2003).

No estudo do comprometimento organizacional, há duas perspectivas dominantes: a afetiva e a instrumental. O estudo do comprometimento organizacional encontra-se largamente dominado pela abordagem "atitudinal/afetiva" (MOWDAY, STEERS e PORTER, 1979; BASTOS, 1994; BASTOS e COSTA, 2000; SIQUEIRA, 2001; FOSSÁ e SARTORETTO, 2002; MEDEIROS, ALBUQUERQUE e MARQUES, 2004), que enfatiza a natureza afetiva do processo de identificação do indivíduo com os objetivos e valores da organização e o desejo de manter-se como membro, de modo a facilitar a consecução desses objetivos.

De acordo com Bastos (1994), a segunda grande abordagem entende o comprometimento em função das recompensas e custos associados com a condição de membro da organização, sendo chamada de instrumental, calculativa, continuação ou sidebets. Os estudos de Becker são apontados pelos estudiosos da área (BASTOS, 1994; MEDEIROS e ENDERS, 1997; MORAES et al., 1997; MEDEIROS e ENDERS, 1998; MEDEIROS et al., 1999; TAMAYO et al., 2000; SIQUEIRA, 2001; FOSSÁ e SARTORETTO, 2002; MEDEIROS et al., 2002; SIQUEIRA e GOMIDE JÚNIOR, 2004) como a origem do comprometimento instrumental, descrito como uma tendência do indivíduo a permanecer na organização - ação consistente -, devido a percepções individuais sobre custos e benefícios associados a sua saída, que seriam as trocas laterais.

As duas perspectivas dominantes no estudo do comprometimento organizacional afetiva e instrumental - partilham uma mesma estratégia metodológica: "usam largamente estudos de corte-transversal, desenvolvem escalas para mensurar os diversos construtos envolvidos nos modelos teóricos submetidos a teste e recorrem à análise quantitativa dos dados obtidos" (BASTOS, 1994, p. 44). 


\subsection{Uma perspectiva multidimensional de comprometimento: múltiplos focos e bases}

O estudo do comprometimento aponta para a investigação de como são articulados os múltiplos vínculos dos indivíduos com variados aspectos do trabalho. Dentre esses aspectos, conhecidos como os focos de comprometimento, estão: o trabalho, a profissão, o grupo de trabalho, o sindicato, a organização empregadora, sendo esta a mais estudada. Além dos focos de comprometimento, outra vertente de estudo apresenta-se como importante: as bases do comprometimento, a exemplo de afetiva, instrumental e normativa. Estas exploram como os diferentes processos psicológicos embasam o vínculo do trabalhador em relação ao foco organização. Dentro de uma perspectiva multidimensional no estudo do comprometimento, busca-se articular estas duas vertentes: os múltiplos focos e as múltiplas bases.

Determinados a aumentar a contribuição teórica e prática do comprometimento, pesquisadores passaram a percebê-lo como um conceito multidimensional (COHEN, 2003). Em consonância com o movimento de afirmação da perspectiva multidimensional no estudo do comprometimento, começaram a aparecer trabalhos que tentam articular as duas vertentes deste movimento: os múltiplos focos e as múltiplas bases (BECKER e BILLINGS, 1993; CARVALHO, 2000; DIAS e MARQUES, 2002; SCHEIBLE, 2004). Em suas pioneiras pesquisas, Becker (1992) estabelece, de forma clara, a distinção entre focos e bases do comprometimento, permitindo colocar em perspectiva a grande dispersão de estudos e fixando, simultaneamente, os dois eixos básicos sob os quais os estudos na área poderiam incorporar as idéias de 'estrutura', 'padrões', 'perfis' ou, em síntese, múltiplos compromissos. Bastos e Costa (2000) justificam o estudo do comprometimento enquanto padrões atitudinais, baseados no fato de que, no mundo do trabalho, as pessoas estão continuamente sob demandas de compromisso, muitas vezes conflitantes, de diferentes entidades. Dessa forma, as decisões pessoais são mais bem compreendidas quando essas múltiplas fontes são examinadas conjuntamente. De acordo com Cohen (2003), o comprometimento no trabalho pode ser mais bem elucidado a partir de uma abordagem multidimensional e, consequentemente, proporcionar melhores preditores do comportamento, superando muitas limitações da tradicional pesquisa sobre comprometimento.

Em um estudo considerando bases e focos do comprometimento, Becker e Billings (1993) investigaram a existência de padrões de comprometimento entre trabalhadores de uma indústria de suprimentos militares. Foram considerados quatro focos (organização, topo gerencial, supervisores imediatos e grupo de trabalho) e três bases (internalização, identificação e obediência). Quando consideradas as bases do compromisso, várias diferenças e similaridades foram encontradas nos quatro padrões de comprometimento com a organização, identificados a partir do uso do procedimento de análise de cluster. Foram observadas diferenças significativas entre os padrões quanto às variáveis dependentes - satisfação, intenção de sair e comportamentos prossociais no trabalho -, demográficas e contextuais.

Já Dias e Marques (2002) articularam simultaneamente os focos (organização e carreira) e as bases (afetiva, instrumental e normativa), em um trabalho com profissionais e gerentes de uma grande empresa do setor metal-mecânico. Quando analisadas as cinco dimensões separadamente, os autores observaram que todos os níveis funcionais tenderam a ser mais comprometidos afetivamente, estando os supervisores mais focalizados na organização, enquanto

${ }^{2}$ Para uma discussão mais ampla sobre as diferentes formas de construtivismo, veja Hacking (1999). 
os analistas e gerentes direcionados tanto para a organização, quanto para a carreira. Os autores verificaram também que quanto maior o grau de atendimento da empresa às expectativas dos empregados, maior o nível de comprometimento. Articulando também múltiplos focos (organização e carreira) e bases (afetiva e instrumental), Scheible (2004) analisou as relações entre o padrão de comprometimento com a organização e a carreira/profissão dos indivíduos, que trabalham em um ambiente de desenvolvimento de software, e seus desempenhos. A autora afirma que os padrões de comprometimento que melhor caracterizam estes profissionais são o duplo compromisso e o unilateral com a organização, e aponta para uma correlação positiva entre comprometimento afetivo com a organização e desempenho auto relatado.

Ao analisar os avanços e as lacunas que o estudo do comprometimento organizacional obteve nos últimos anos no Brasil, Medeiros etal. (2002) apontam a abordagem multidimensional, com múltiplos focos e bases, como uma busca para entender os indivíduos e seu vínculo com a organização de uma maneira mais complexa, sendo considerada um dos novos desafios para a pesquisa na área. Demo (2003) corrobora esta idéia, destacando a premência de se realizar pesquisas que integrem as múltiplas bases e focos do constructo e combinem diferentes perspectivas metodológicas para se entender o tema com maior propriedade.

\subsection{Antecedentes do comprometimento no trabalho}

A identificação, simultânea ou não, de fatores antecedentes, de outros conceitos correlatos e de fatores consequentes do comprometimento, tem se mostrado um importante objetivo neste campo de estudo. Algumas pesquisas da área (MOWDAY, PORTER e STEERS, 1982; MATHIEU e ZAJAC, 1990; BASTOS, 1994; TAMAYO et al., 2001; SIQUEIRA E GOMIDE JÚNIOR, 2004; SCHEIBLE, 2004) e duas recentes revisões (COOPER-HAKIM e VISWESVARAN, 2005; MEYER et al., 2002) vêm discutindo os antecedentes, correlatos e consequentes, e nortearam as afirmações seguintes.

São inúmeras as variáveis consideradas antecedentes ou preditoras do comprometimento que podem ser agrupadas em grupos como: características pessoais, características do trabalho e características organizacionais. Dentre as características pessoais, são estudadas variáveis como: sexo, estado civil, idade, escolaridade, tempo no cargo, tempo na organização, percepção de competência, habilidades, salário e nível do cargo. As características do trabalho são: autonomia na tarefa, variedade de habilidades, desafio e desenho do cargo. Já entre as características organizacionais são estudadas: tamanho e centralidade.

Maiores níveis de comprometimento tendem a estar associados com: mulheres e pessoas casadas, maiores medidas de idade, tempo na organização, nível ocupacional, remuneração, menores medidas de escolaridade, características de trabalho inovador e não rotineiro, estilo participativo da gerência e liderança com habilidade de comunicação. Deve-se atentar para o fato de que diferentes tipos de comprometimento, seja frente a focos seja a bases, podem estar associados a vários e distintos fatores antecedentes, correlatos e consequentes.

De acordo com Siqueira e Gomide Júnior (2004), as pesquisas sobre os antecedentes do comprometimento afetivo têm revelado que empregados comprometidos afetivamente são os que apresentam menores taxas de rotatividade, absenteísmo e intenção de sair da empresa, bem como melhores indicadores de desempenho no trabalho. Já quando o comprometimento afetivo é baixo, são observados atrasos, fraco desempenho e esforço reduzido aplicado ao trabalho. No que diz respeito ao comprometimento instrumental, verifica-se que trabalhadores que percebem altos custos associados ao seu desligamento das organizações - mais comprometidos instrumentalmente - tendem a ser menos motivados e a apresentar mais baixos 
níveis de desempenho no trabalho do que aqueles para quem os custos percebidos seriam em níveis mais baixos.

No presente artigo, dentro de uma perspectiva multidimensional do comprometimento, foram investigados os vínculos frente a dois focos (trabalho e organização) e a duas bases (afetiva e instrumental), e sua relação com possíveis antecedentes e correlatos, entre trabalhadores de organizações agrícolas do polo Juazeiro/Petrolina.

\section{4 As organizações agrícolas do polo Juazeiro/Petrolina}

O mundo do trabalho vem passando por intensas mudanças, trazendo para as organizações e trabalhadores o novo: novas tecnologias estão sendo incorporadas aos processos de trabalho; emergem novos modelos de gestão; novas relações de trabalho são estabelecidas; novos vínculos de compromisso vêm sendo desenvolvidos. Mudanças também vêm sendo vivenciadas no meio agrário brasileiro. Estruturado com base em forte concentração de capital, com ênfase na exportação (ALBUQUERQUE, 2002), o processo de modernização agrária do Brasil, em especial, no polo Juazeiro/Petrolina, envolve a adoção de técnicas modernas de produção e de gestão do trabalho (FISCHER, 2000).

As mudanças no meio rural suscitam um amplo debate, no meio científico, em busca de um novo conceito de espaço rural, que tem sido denominado por muitos autores de "novo rural" (BAIARDI, 1998; DUFUMIER e COUTO, 1998; SEI, 2002; SEI, 2003). Um dos aspectos do novo mundo rural, de acordo com Baiardi (1998), expressa-se na tendência de reorganização produtiva e hegemonização de novos paradigmas de produção, os quais refletem as inovações tecnológicas, as novas exigências de consumo e a lógica da competição em mercados globais. Estabelece-se, conjuntamente, no meio rural, uma evolução tecnológica no setor agrícola, uma reorganização dos processos de produção e de trabalho, e uma interação entre as atividades nos espaços rural e urbano (SEl, 2003).

De acordo com Favero (1998), ocorreu uma ruptura entre o rural - espaço social - e o agrícola - sistema de produção -, descaracterizando o meio rural como um lugar estritamente relacionado à produção agrícola. Dessa forma, para se desenvolver, a agricultura deveria se integrar à indústria. O trabalho no meio rural deixa, portanto, de corresponder somente às atividades agrícolas e passa a incorporar outras atividades não agrícolas, como a indústria e os serviços, antes percebidas apenas como atividades do meio urbano (DUFUMIER e COUTO, 1998; NAVARRO, 2000).

A região do polo Juazeiro/Petrolina foi pioneira na implantação dos grandes projetos públicos - a exemplo do Nilo Coelho, Mandacaru, Maniçoba e Curaçá - e privados de irrigação, o que gerou a consolidação e expansão de uma atividade agrícola integrada à indústria. Esta região está situada no Baixo Médio São Francisco - semi-árido nordestino -, na porção central do polígono das secas, nos estados da Bahia - porção setentrional - e de Pernambuco - ao sudoeste.

De acordo com Fischer (2000), a região é beneficiada por políticas públicas de geração de energia e de irrigação, que possibilitaram a implantação de uma infraestrutura que tem proporcionado o desenvolvimento econômico da região. Por suas significativas vantagens comparativas - disponibilidade de terra e de água de boa qualidade em quantidade suficiente; mão de obra abundante; condições edafoclimáticas favoráveis; maior proximidade dos mercados europeu e norte-americano comparada à região Sudeste -, a região do polo Juazeiro/Petrolina se apresenta como uma das áreas de desenvolvimento do complexo agroindustrial, que tem 
atraído o interesse crescente de governos e de investidores privados, internos e externos, de vários elos das cadeias produtivas (FRANÇA, PEREIRA NETO e MEIRA, 199-).

A modernização agrícola, via irrigação, envolve a adoção de técnicas modernas de produção e de gestão do trabalho, como: o uso de implementos e técnicas agrícolas modernos; a adição de técnicas modernas de manejo do solo; a utilização de vultosos volumes de capital; a realização de pesquisas agropecuárias no campo da genética, da química - adubos e corretivos -, no âmbito fitossanitário e em irrigação (FISCHER, 2000). O desenvolvimento tecnológico, característico da fruticultura no Baixo-Médio São Francisco, que fomentou o crescimento da produção agrícola com práticas modernas de manejo do solo e irrigação, é considerado como um fator dinamizador da agricultura do Estado da Bahia (SEI, 2001).

Apesar de haver uma tendência ao desemprego no campo, em razão, principalmente, das modernas tecnologias - a exemplo da cultura da cana-de-açúcar, com uso de máquinas desde o plantio até o corte -, a fruticultura irrigada se apresenta como um dos casos de geração de emprego resultante de avanços tecnológicos (SEI, 2002; SEI, 2003; GUERREIRO, 2003). Para França, Pereira Neto e Meira (199-), a ação sistêmica da agribusiness gera eficiência, competitividade e maior agregação de valor à produção local, permitindo incrementos expressivos de emprego e de renda.

Segundo Guerreiro (2003), o segmento da fruticultura pode ser considerado um "negócio agrícola ou complexo agroindustrial", porque envolve um conjunto de atividades e interesses comuns, que vão do sistema de produção às cadeias produtivas. As organizações, nos polos irrigados do Nordeste, dentro desta complexa cadeia produtiva, podem assumir apenas um, dois ou mesmo três dos processos seguintes: produzir, processar e comercializar.

A empresa produtora é responsável por atividades como o plantio, a irrigação e a colheita em relação a diversas culturas. O novo padrão agrário introduziu culturas não tradicionais na região e de alto valor comercial, destinadas à exportação ou processamento industrial, a exemplo da uva e da manga (GUERREIRO, 2003). Os mercados consumidores internacionais fazem uma série de exigências de padrões e condutas, produtivas e de gestão, que impõem aos produtores parâmetros referentes aos tratos culturais pré e pós-colheita (LIMA e MIRANDA, 2000; GUERREIRO, 2003).

A empresa que cumpre a função relacionada ao beneficiamento é aquela que recebe o produto - ou já o possui - e o beneficia ou processa, dando-lhe marca, especificações de qualidade, entre outros atributos. Para o beneficiamento, são utilizados os packing houses - casas de empacotamento - que realizam os seguintes processos: lavagem e purificação; tratamento hidrotérmico para eliminação da "doença da mosca"; classificação; resfriamento e armazenagem das frutas em câmaras frias, adaptando o produto às exigências do cliente externo e aumentando a sua durabilidade para suportar longas travessias até os mercados da União Europeia.

Com relação à comercialização, existem empresas que vêm se especializando apenas neste processo, principalmente para o mercado internacional. A comercialização in natura da produção de frutas, tanto para o mercado externo como para o interno, garante a maior movimentação comercial (GUERREIRO, MATTA e MACÊDO, 2002; GUERREIRO, 2003). Para algumas organizações agrícolas associadas, a estratégia de comercialização é definida pela VALEXPORT, organização representativa do setor agrícola empresarial, com sede em Petrolina, $\mathrm{PE}$, que inclui, entre seus objetivos, o desenvolvimento da pesquisa agropecuária e a defesa dos interesses dos agricultores locais (FAVERO, 1998).

As transformações na região foram acompanhadas, ainda, por mudanças nas relações de trabalho, com uma tendência ao crescimento de relações assalariadas (FISCHER, 2000; LIMA 
e MIRANDA, 2000), propiciadas pela regularização temporal da produção e pela expansão da área cultivada. Para Fischer (2000), ocorre, na região, uma transformação nos meios de produção, que redefine as relações de trabalho, substituindo, por exemplo, a parceria - na qual trabalhadores são remunerados em quota-parte da produção obtida com seu trabalho - pela relação de trabalho baseada no assalariamento - trabalhadores recebem o pagamento através de uma quantia prefixada em dinheiro -, que desvincula o trabalhador dos meios de produção.

\subsection{Delimitação do problema investigado}

Embora a pesquisa sobre comprometimento no trabalho tenha uma longa tradição, inclusive no Brasil, seus resultados descrevem a realidade do trabalhador urbano e dos segmentos industrial e de serviço. Inexistem dados que revelem os níveis e a natureza dos vínculos de comprometimento entre trabalhadores agrícolas e suas organizações. Adicionalmente, faltam estudos que analisem tal fenômeno em um contexto de profundas alterações tecnológicas e organizacionais com amplas consequências econômicas, sociais e culturais para uma região historicamente subdesenvolvida.

Ao tomar trabalhadores de organizações agrícolas como unidade de análise, a presente investigação tem como objetivo descrever os níveis de comprometimento dos trabalhadores com o trabalho, com a organização empregadora, identificando o peso dos elementos afetivos e instrumentais como bases para a sua relação com esta, relacionando-os a características pessoais e relativas ao trabalho.

\section{Método: decisões sobre o desenvolvimento da pesquisa}

A investigação adotou uma estratégia metodológica apoiada na tradição de estudos sobre comprometimento no trabalho, caracterizando-se como um estudo extensivo com delineamento de corte-transversal.

Foi entrevistado, aproximadamente, $10 \%$ do quadro de empregados de 32 organizações agrícolas de médio ou grande porte do polo Juazeiro/Petrolina, totalizando 919 trabalhadores. Dentre os participantes da pesquisa, $71,3 \%$ são trabalhadores permanentes e $28,7 \%$ temporários. Participaram representantes de todas as atividades desenvolvidas nas organizações: administrativas $(8,8 \%)$, de packing houses $(9,8 \%)$, técnicas $(16,6 \%)$, e a maioria se concentra em atividades de campo $(64,6 \%)$. Pode-se observar que há um predomínio do sexo masculino $(66,5 \%)$, de pessoas casadas ou que possuem um companheiro $(57,3 \%)$, de jovens (59,9\% possuem até 30 anos) e de pessoas com pouca escolaridade (57,0\% estudaram, no máximo, até o antigo curso primário completo).

Os dados foram coletados através de entrevistas, guiadas por um questionário composto, predominantemente, de itens fechados. As medidas de comprometimento utilizadas (comprometimento com a organização, comprometimento com o trabalho, comprometimento afetivo e comprometimento instrumental) foram mescladas, perfazendo um total de 31 itens avaliados em uma escala tipo Likert, variando de 1 (discordo muito) a 7 (concordo muito) pontos. Para medir a variável comprometimento com o trabalho, foi utilizada a escala de dez itens proposta por Fink (1992). Essas medidas foram utilizadas por Bastos (1998), obtendo elevados indicadores de confiabilidade $(\alpha=0,84)$. No presente estudo, foram excluídos quatro itens no intuito de aumentar o alfa de Cronbach para $\alpha=0,66$.

A variável comprometimento com a organização foi mensurada a partir da versão reduzida da escala de Mowday, Porter e Steers (1982), com nove itens. Esta escala foi traduzida 
e adaptada para o contexto brasileiro por Borges-Andrade, Afanasieff e Silva (1989), e seus itens obtiveram um bom índice de consistência interna, com um coeficiente alfa de Cronbach de $a=0,855$ (BASTOS, 1994). Neste estudo, o alfa de Cronbach encontrado foi de $a=0,84$.

Para medir as bases do comprometimento organizacional, foram utilizadas as escalas de comprometimento propostas por Meyer e Allen (1997), compostas por seis itens para cada base, que visam a avaliar a natureza afetiva e instrumental do comprometimento com a organização. As medidas acerca das bases foram previamente validadas para o contexto nacional por Medeiros e Enders (1997). Os valores de alpha de Cronbach para o fator afetivo foi de $\alpha=0,68$ e, para o fator instrumental, de $\alpha=0,61$. Já os valores de alpha de Cronbach, no presente estudo, foram de $\alpha=0,81$ e $\alpha=0,61$, respectivamente.

Foram também levantados dados de caracterização pessoal e de caracterização relativos ao trabalho, que possibilitaram verificar a associação destes ao constructo investigado, além de permitirem traçar um perfil dos trabalhadores. Em linhas gerais, o roteiro de entrevista estruturado contém medidas de dados pessoais, como: sexo, estado civil, idade, escolaridade. No que se refere a variáveis pessoais ligadas ao trabalho, questionou-se sobre: a importância atribuída ao trabalho - medida desenvolvida pelo MOW (1987) para medir a centralidade do trabalho e o grau de apego ao trabalho -, grau de satisfação com o trabalho e obediência às ordens dos superiores. Dentre os dados de caracterização relativos ao trabalho, foram investigados: o tipo de atividade desenvolvida no trabalho, a duração do contrato e o tempo de serviço na organização, no caso de trabalhadores permanentes.

Os instrumentos foram objeto de um novo processo de adaptação ao contexto específico dos trabalhadores das organizações agrícolas do polo Juazeiro/Petrolina. Os níveis de escolaridade e as especificidades culturais do setor agrário demandaram ajustes importantes nas ferramentas disponíveis, até então utilizadas em contextos urbanos e com trabalhadores com maiores níveis de escolaridade. Foram utilizados recursos não-verbais, com uso de cores e quantidades em substituição às escalas tradicionais, viabilizando a utilização de escala Likert com esta população. Em virtude da baixa escolaridade dos respondentes, todo o procedimento de coleta de dados envolveu o uso de entrevista, e não a aplicação de questionário, que é o método mais usual. Portanto, a coleta de dados foi realizada através de entrevistas guiadas por um questionário estruturado, no local de trabalho e no horário do expediente. Durante a realização da pesquisa, foram tomadas as providências necessárias para garantir a integridade ética dos participantes da pesquisa.

O processo de análise se iniciou com as codificações das respostas e a preparação do banco de dados, com a utilização do Statistical Package for Social Science (SPSS_for Windows. Foram realizadas análises estatísticas descritivas. Testes de diferenças entre médias, através da prova T de Student e da análise de variância - ANOVA -, foram empregados para avaliar as diferenças entre segmentos da amostra. Para as comparações múltiplas, foi utilizado o método de Scheffé. Foram consideradas estatisticamente significantes as diferenças que apresentaram um $\mathrm{p}<0,05$.

\section{Resultados e discussão}

Em se tratando de um estudo que busca conhecer um segmento de trabalhadores sobre o qual não se tem dados sobre comprometimento, os resultados, neste momento, são apresentados tendo em vista fornecer esse quadro descritivo geral, comparando-o com o que a literatura já fornece em relação a outros segmentos. 
Os níveis de comprometimento encontrados frente aos dois focos (6,42 - trabalho e 5,83 - organização) e às duas bases (5,30 - afetiva e 5,22 - instrumental) se colocam em patamares dos mais elevados, quando se tomam os estudos disponíveis no Brasil. O vínculo com a atividade de trabalho desenvolvida se apresenta mais forte entre os trabalhadores do que o vínculo com a empresa empregadora. Com relação às bases, observa-se um vínculo afetivo maior do que um instrumental. Os elevados níveis, todos acima de cinco, em uma escala de sete pontos, podem ser mais bem compreendidos após a análise dos múltiplos comprometimentos em relação às diferentes características pessoais e relativas ao trabalho dos participantes. Deve-se atentar também para o fato de que as organizações em estudo são empresas agrícolas modernas, intensivas em capital e mão de obra, que vêm atraindo trabalhadores rurais das zonas rurais circunvizinhas, sendo consideradas, na região, como uma excelente oportunidade de emprego.

A Tabela 1 apresenta as médias dos diferentes tipos de comprometimento por algumas características pessoais - sexo, estado civil, idade e escolaridade -.

Tabela 01 - Médias de comprometimento por características pessoais

\begin{tabular}{|c|c|c|c|c|c|}
\hline \multirow[t]{2}{*}{ Variáveis } & \multirow[t]{2}{*}{$\%$} & \multicolumn{2}{|c|}{$\begin{array}{c}\text { Comprometimento } \\
\text { com os focos }\end{array}$} & \multicolumn{2}{|c|}{$\begin{array}{l}\text { Comprometimento } \\
\text { com as bases }\end{array}$} \\
\hline & & Trabalho & Organização & Afetiva & Instrumental \\
\hline \multicolumn{6}{|l|}{ Sexo } \\
\hline Masculino & 66,5 & $6,39 *$ & 5,83 & 5,31 & 5,21 \\
\hline Feminino & 33,5 & 6,49 & 5,84 & 5,27 & 5,23 \\
\hline \multicolumn{6}{|l|}{ Estado Civil } \\
\hline Solteiro & 37,3 & $6,31 * * *$ & $5,65 * * *$ & $5,06 * * *$ & $4,91 * * *$ \\
\hline Casado/vive junto & 57,3 & 6,48 & 5,93 & 5,40 & 5,38 \\
\hline Outro (separado, viúvo) & 5,3 & 6,62 & 6,05 & 5,83 & 5,57 \\
\hline \multicolumn{6}{|l|}{ Idade } \\
\hline Até 25 anos & 39,7 & $6,30 * * *$ & $5,57 * * *$ & $4,96 * * *$ & $4,99 * * *$ \\
\hline De 26 a 35 anos & 34,9 & 6,48 & 5,93 & 5,38 & 5,22 \\
\hline Acima de 36 anos & 25,5 & 6,55 & 6,10 & 5,70 & 5,57 \\
\hline \multicolumn{6}{|l|}{ Escolaridade } \\
\hline Até primário incompleto & 6,3 & $6,57 * *$ & $5,99 *$ & $5,52 * *$ & $5,66 * * *$ \\
\hline Primário completo & 57,0 & 6,44 & 5,89 & 5,33 & 5,41 \\
\hline Ginásio completo & 17,8 & 6,26 & 5,59 & 4,93 & 5,01 \\
\hline Médio completo & 16,1 & 6,47 & 5,82 & 5,44 & 4,81 \\
\hline Superior completo & 2,8 & 6,60 & 5,91 & 5,67 & 3,99 \\
\hline
\end{tabular}

$*(p<0,05) \quad * *(p<0,01) \quad * * *(p<0,001)$

Não foram encontradas diferenças estatisticamente significantes entre 'homens' e 'mulheres' em relação ao comprometimento com a organização, assim como em relação ao comprometimento afetivo e instrumental. No entanto, observa-se que as 'mulheres' apresentam maior média de comprometimento com o trabalho $(6,49)$ do que os 'homens' $(6,39)$. As comparações entre trabalhadores do sexo masculino e feminino aparecem, frequentemente, nas pesquisas acerca do comprometimento no trabalho, por possibilitarem, de acordo com Bastos (1994), a tradução de histórias e normas culturais que diferenciam a relação de homens e mulheres com o trabalho. A tendência, apontada por alguns autores (MATHIEU e ZAJAC, 1990; FINK, 1992), de que as mulheres são mais comprometidas do que os homens, foi verificada 
apenas com relação ao comprometimento com o trabalho. Este dado pode ser discutido a partir de reflexões acerca da relação das mulheres com o trabalho na região. De acordo com Branco e Vainsencher (2001), as mulheres vivenciam uma grande mudança ao serem inseridas nas relações de trabalho, estabelecidas na esfera pública, que envolvem o acesso a uma remuneração. O trabalho que grande parte das mulheres realizava antes do assalariamento, muitas vezes pesado, estava circunscrito aos limites do espaço privado, ao rol das atividades domésticas, portanto, não era remunerado, sendo descaracterizado como trabalho produtivo. Segundo as autoras, esta nova forma de inserção laboral remunerada produz tamanha satisfação, que as mulheres passam a desconsiderar como árduas as atividades que realizam na fruticultura. Além disso, este trabalho promove uma mudança positiva no que diz respeito à autoimagem. Antes submissas e dependentes dos homens, as mulheres passaram, inclusive, a serem preferidas pelos empresários para algumas das atividades produtivas da fruticultura, a exemplo do raleio da uva, pelo cuidado artesanal que tal atividade exige.

Os 'solteiros' são menos comprometidos do que os 'casados' e do que os 'separados e viúvos', no que se refere aos quatro tipos de comprometimento investigados, dado que corrobora estudos da literatura da área (MATHIEU e ZAJAC, 1990) e a análise de que demandas oriundas de responsabilidades familiares levam a maiores níveis de comprometimento.

No que se refere à idade, os trabalhadores mais jovens - 'até 25 anos' - são menos comprometidos com o trabalho $(6,30)$ e com a organização $(5,57)$ do que os adultos jovens - 'de 26 a 35 anos' (6,48 e 5,93, respectivamente) e do que os mais velhos - 'acima de

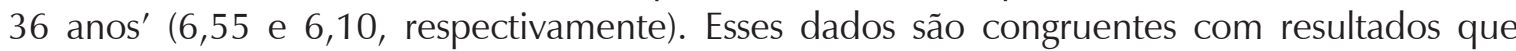
associam maior idade a maior comprometimento com a organização (MATHIEU e ZAJAC, 1990; BASTOS, 1994). Já os adultos jovens - 'de 26 a 35 anos' - são mais comprometidos afetivamente $(5,38)$ e instrumentalmente $(5,22)$ do que os mais jovens - 'até 25 anos' $(4,96$ e 4,99 , respectivamente) e menos comprometidos do que os mais velhos - acima de 36 anos (5,70 e 5,57, respectivamente). É possível que os mais jovens desenvolvam menor vínculo por possuírem menores responsabilidades familiares e maiores perspectivas de futuro. Os mais velhos esbarram nas limitações relativas à idade, que dificultam encontrar um novo emprego, seja no mesmo tipo de trabalho seja em atividades diferenciadas. No caso dos trabalhadores rurais, há uma preferência pelos mais jovens, em razão de o trabalho ser considerado pesado, e o deslocamento para outras atividades requer, por vezes, um duro investimento na aprendizagem destas, que foge a toda uma longa história laboral, que já forneceu ao indivíduo uma identidade como trabalhador.

Quanto à 'escolaridade', observa-se que os trabalhadores com o 'primário completo' apresentam um maior comprometimento com a organização $(5,89)$ do que os trabalhadores com o 'ginásio completo' $(5,59)$. No que diz respeito à base afetiva, os trabalhadores com o 'ginásio completo' apresentam menor comprometimento $(4,93)$ do que os trabalhadores com o 'primário completo' $(5,33)$ e com o 'médio completo' $(5,44)$. Na base instrumental, verificase que os trabalhadores com o 'ginásio completo' são menos comprometidos $(5,01)$ do que os com 'primário completo' $(5,41)$ e do que os trabalhadores com até o primário incompleto $(5,66)$. No entanto, os trabalhadores com o 'ginásio completo' são mais comprometidos do que aqueles com 'superior completo' $(3,99)$. Estes são menos comprometidos instrumentalmente do que todas as demais faixas de escolaridade. Realizando uma análise apenas descritiva, podese observar que trabalhadores com o 'ginásio completo' apresentam os menores índices de comprometimento com o trabalho, com a organização e afetivamente, e os índices se elevam tanto na medida em que diminui, quanto na medida em que aumenta a escolaridade. Esta tendência não é observada no comprometimento instrumental, no qual predomina a relação 
negativa entre escolaridade e comprometimento: quando aumenta a escolaridade, diminuem os índices de comprometimento. Isto pode ser explicado pelo fato de que indivíduos com maiores níveis de escolaridade possuem mais expectativas em relação à organização, bem como mais opções de emprego (MOWDAY, PORTER e STEERS, 1982).

As médias dos diferentes tipos de comprometimento por 'importância atribuída ao trabalho', 'satisfação com o trabalho' e 'obediência às ordens' estão apresentadas na Tabela 2. Com relação à importância do trabalho, os trabalhadores que atribuem uma elevada importância ao trabalho são os mais comprometidos com o trabalho $(6,48)$, com a organização $(5,91)$ e afetivamente $(5,39)$. Estes trabalhadores também são mais comprometidos instrumentalmente $(5,27)$ do que os trabalhadores que atribuem uma moderada importância ao trabalho $(4,92)$. Como esperado, indivíduos que consideram o trabalho como algo mais central em suas vidas, desenvolvem vínculos mais fortes com a atividade de trabalho desempenhada, assim como com a empresa para a qual trabalham.

Quanto maior é a satisfação dos grupos de trabalhadores com o trabalho, maiores são os escores de comprometimento com o trabalho, com a organização e afetivamente. No caso do comprometimento instrumental, observa-se que os trabalhadores com elevada satisfação com o trabalho são mais comprometidos $(5,37)$ do que os de baixa $(4,63)$ e os de moderada satisfação $(4,97)$. Por estarem mais satisfeitos com o trabalho, os indivíduos também desenvolvem vínculos de compromisso mais fortes, seja com o trabalho desempenhado, seja com a empresa empregadora, como é possível presumir.

Tabela 2 - Médias de comprometimento por características pessoais relacionadas ao trabalho

\begin{tabular}{|c|c|c|c|c|c|}
\hline \multirow[t]{2}{*}{ Variáveis } & \multirow[t]{2}{*}{$\%$} & \multicolumn{2}{|c|}{$\begin{array}{l}\text { Comprometimento } \\
\text { com os focos }\end{array}$} & \multicolumn{2}{|c|}{$\begin{array}{c}\text { Comprometimento } \\
\text { com as bases }\end{array}$} \\
\hline & & Trabalho & Organização & Afetiva & Instrumental \\
\hline \multicolumn{6}{|c|}{ Importância do trabalho } \\
\hline Baixa & 2,9 & $5,98 * * *$ & $5,26 * * *$ & $4,73 * * *$ & $4,99 * *$ \\
\hline Moderada & 12,8 & 6,19 & 5,46 & 4,80 & 4,92 \\
\hline Elevada & 84,2 & 6,48 & 5,91 & 5,39 & 5,27 \\
\hline \multicolumn{6}{|c|}{ Satisfação com o trabalho } \\
\hline Baixa & 6,1 & $5,85 * * *$ & $4,42 * * *$ & $3,70 * * *$ & $4,63 * * *$ \\
\hline Moderada & 27,9 & 6,16 & 5,40 & 4,74 & 4,97 \\
\hline Elevada & 66,1 & 6,59 & 6,15 & 5,68 & 5,37 \\
\hline \multicolumn{6}{|c|}{ Obediência às ordens } \\
\hline Sempre & 50,8 & $6,50 * *$ & $5,91 *$ & 5,39 & $5,38 * * *$ \\
\hline Só convencido & 42,4 & 6,33 & 5,72 & 5,19 & 5,12 \\
\hline Depende & 6,7 & 6,41 & 5,93 & 5,29 & 4,57 \\
\hline
\end{tabular}

$*(p<0,05) \quad * *(p<0,01) \quad * * *(p<0,001)$

Verifica-se que os trabalhadores que acham que devem sempre cumprir as ordens dos superiores, mesmo quando não concordam com elas, são mais comprometidos com o trabalho $(6,50)$ e com a organização $(5,91)$, do que os trabalhadores que acham que só devem cumprir as ordens quando estão convencidos de que são corretas (6,33 e 5,72, respectivamente). Esta mesma tendência é observada com relação ao comprometimento instrumental com a organização, cujas médias dos trabalhadores que acreditam dever sempre cumprir as ordens são maiores $(5,38)$ do que as daqueles para os quais o cumprimento da ordem requer estar convencido da sua correção $(5,12)$. Tal resultado, associado ao fato de se ter identificado níveis 
tão elevados de comprometimento, mesmo entre trabalhadores com vínculos bastante precários, deverá levar a uma reflexão, ausente na literatura científica, sobre os limites e interfaces entre comprometimento e obediência. Assim, tais escores podem estar refletindo uma cultura de obediência que remonta ao secular padrão de exploração agrária dominante no nordeste.

Na Tabela 3, são apresentadas as médias dos diferentes tipos de comprometimento por características relativas ao trabalho: tipo de atividade desenvolvida; duração do contrato; vezes que trabalhou na organização, no caso dos trabalhadores temporários; e tempo de serviço na organização, no caso de trabalhadores permanentes.

Tabela 3 - Médias de comprometimento por características relativas ao trabalho

\begin{tabular}{|c|c|c|c|c|c|}
\hline \multirow[t]{2}{*}{ Variáveis } & \multirow[t]{2}{*}{$\%$} & \multicolumn{2}{|c|}{$\begin{array}{l}\text { Comprometimento } \\
\text { com os focos }\end{array}$} & \multicolumn{2}{|c|}{$\begin{array}{l}\text { Comprometimento } \\
\text { com as bases }\end{array}$} \\
\hline & & Trabalho & Organização & Afetiva & Instrumental \\
\hline \multicolumn{6}{|l|}{ Atividades } \\
\hline Administrativas & 8,8 & $6,61 * *$ & $6,05 * *$ & $5,74 * * *$ & $4,69 * * *$ \\
\hline Técnicas & 16,6 & 6,51 & 6,05 & 5,64 & 5,24 \\
\hline De campo & 64,6 & 6,37 & 5,76 & 5,15 & 5,28 \\
\hline De packing house & 9,8 & 6,46 & 5,78 & 5,27 & 5,21 \\
\hline \multicolumn{6}{|l|}{ Duração do contrato } \\
\hline Determinada (temporário) & 28,7 & 6,45 & 5,79 & 5,24 & 5,33 \\
\hline Indeterminada (permanente) & 71,3 & 6,41 & 5,85 & 5,32 & 5,17 \\
\hline \multicolumn{6}{|l|}{$\begin{array}{l}\text { Tempo na empresa } \\
\text { para os permanentes }\end{array}$} \\
\hline Até 1 ano & 36,2 & $6,37 *$ & $5,76 * *$ & $5,12 * * *$ & $5,22 * *$ \\
\hline Acima de 1 a 5 anos & 45,8 & 6,38 & 5,82 & 5,31 & 5,02 \\
\hline Acima de 5 a 9 anos & 10,7 & 6,55 & 6,12 & 5,74 & 5,46 \\
\hline Acima de 9 anos & 7,3 & 6,60 & 6,17 & 5,88 & 5,48 \\
\hline
\end{tabular}

$*(p<0,05) \quad * *(p<0,01) \quad * * *(p<0,001)$

Os trabalhadores que desenvolvem 'atividades administrativas' são mais comprometidos com o trabalho $(6,61)$ do que aqueles que desenvolvem 'atividades de campo' $(6,37)$. Quanto ao comprometimento com a organização, observa-se que os trabalhadores que desenvolvem 'atividades técnicas' são mais comprometidos $(6,05)$ do que aqueles que desenvolvem 'atividades de campo' $(5,76)$. Estes também possuem um comprometimento afetivo menor $(5,15)$ que os trabalhadores que desenvolvem 'atividades técnicas' $(5,64)$ e 'atividades administrativas' $(5,74)$. Com relação ao comprometimento instrumental, verifica-se que os trabalhadores que desenvolvem 'atividades administrativas' são menos comprometidos $(4,69)$ que os trabalhadores que desenvolvem as demais atividades - de packing house $(5,21)$, técnicas $(5,24)$ e de campo $(5,28)$. Os trabalhadores 'de campo', que desempenham as atividades manuais e de menor prestígio social, são os menos comprometidos com o trabalho, com a organização e afetivamente. Isto se inverte no que diz respeito ao comprometimento instrumental, no qual os trabalhadores 'de campo' apresentam os maiores níveis, permitindo a interpretação de que as oportunidades de emprego, os altos custos associados a deixar a organização e, portanto, a necessidade de permanecer na organização afetam o vínculo desses trabalhadores com a organização.

Quando investigados os comprometimentos entre trabalhadores 'temporários' com duração de contrato determinada - e trabalhadores 'permanentes' - com duração de contrato indeterminada - verifica-se que não há diferenças estatisticamente significantes entre 
estes grupos. Segundo Witte e Näswall (2003), resultados referentes ao comprometimento organizacional de trabalhadores com diferentes vínculos contratuais são ambíguos: alguns pesquisadores encontraram uma redução do comprometimento entre empregados temporários, comparados com empregados com contrato permanente; enquanto outros estudos não encontraram diferenças. Os autores, no entanto, levantaram a hipótese de que empregados com um contrato de curta duração, em um processo de comparação com os empregados permanentes, percebem-se em posição desvantajosa, levando a sentimentos de privação e iniquidade, o que resultaria em reduzidos níveis de comprometimento. Esta hipótese não foi confirmada em nenhum dos quatro países europeus estudados - Bélgica, Holanda, Itália e Suécia -, possibilitando a conclusão de que o emprego temporário não é um problema por si mesmo e que pode também possuir alguns fatores positivos, ainda não expostos na literatura.

Quando considerado o 'tempo de serviço na empresa' entre os 'permanentes', verificase que os trabalhadores que possuem mais tempo de serviços na empresa - 'acima de nove anos' - e os que possuem 'acima de cinco a nove anos' são mais comprometidos afetivamente com a organização $(5,88$ e 5,74, respectivamente) do que os que possuem 'até um ano de empresa' $(5,12)$. No geral, observa-se uma tendência a elevação dos níveis de comprometimento à medida que aumenta o tempo de serviço dos trabalhadores na empresa. Maior tempo de serviço na empresa está associado com os níveis mais elevados de comprometimento, como preconizado pela literatura (MATHIEU e ZAJAC, 1990). Tamayo et al. (2001), que também encontraram níveis de comprometimento superiores para trabalhadores com maior tempo de serviço na empresa, sugerem que os anos passados em uma organização contribuem para construir um vínculo afetivo com esta, em razão do investimento pessoal nela realizado pelo empregado, o conhecimento aprofundado da empresa e as amizades desenvolvidas no ambiente do trabalho. Estes autores alertam para o fato de que a relação causal entre tempo de empresa e comprometimento seja recíproca, ou seja, o tempo de empresa influencia positivamente o comprometimento organizacional e, por outro lado, trabalhadores comprometidos com a organização teriam tendência a permanecerem mais tempo nela. A possível associação entre tempo de empresa e idade também é levantada pelos autores, que argumentam que a maturidade psicológica que o empregado desenvolve com a idade pode interferir também no desenvolvimento do vínculo afetivo com a organização.

\section{Considerações finais}

O presente estudo buscou caracterizar os níveis de comprometimento com o trabalho e com a organização e, adicionalmente, a natureza afetiva ou instrumental deste último vínculo, entre um segmento de trabalhadores agrícolas, até então praticamente esquecido pela pesquisa sobre comportamento organizacional. Por se tratar, no país, de um primeiro estudo sobre comprometimento que incorpora tal segmento de trabalhadores, o recorte dos dados, aqui apresentados, implicou em uma caracterização geral de como tais níveis de comprometimento se diferenciam ou não entre vários estratos da amostra estudada.

Além de trazer para cena esse trabalhador agrícola, o estudo conduzido contribui para compreender como os vínculos entre trabalhador, trabalho e organização estão se construindo em um cenário particularmente rico em transformações e complexo, face à histórica desigualdade econômica e social, que caracteriza o sertão nordestino em relação a outras regiões do país.

Neste sentido, pode-se afirmar que a ampliação dos contextos em que fenômenos psicossociais são estudados - inseridos ou não em organizações - se torna uma necessidade para ampliar o corpo de conhecimento em um campo de pesquisa. Esse é o caso dos estudos sobre 
comprometimento, que acumularam, ao longo das duas últimas décadas, um rico conjunto de dados, mas que não tem contemplado a diversidade de organizações e contextos regionais existente no Brasil.

O trabalho, aqui relatado, permite, em um momento inicial, verificar se tendências observadas na literatura estão ou não presentes neste novo contexto de investigação, contribuindo para ampliar ou não o poder de generalização dos nossos enunciados sobre o comprometimento do trabalhador.

Vale destacar que, do conjunto de dados apresentados, pode-se reafirmar a natureza multidimensional do construto de comprometimento. As associações entre variáveis - tanto pessoais quanto do trabalho - revelam alguns padrões diversos quando se tomam os focos (trabalho e organização) e as bases (afetiva e instrumental) do comprometimento do trabalhador. Verificou-se, adicionalmente, que o segmento de trabalhadores de empresas agrícolas se caracteriza por níveis elevados de comprometimento, em alguns casos, superiores àqueles encontrados entre outros segmentos de trabalhadores dos grandes centros urbanos do país. $\mathrm{O}$ trabalhador de campo, que assume as tarefas mais árduas e definidoras do tradicional trabalho rural, no entanto, apresenta, relativamente aos demais grupos, um vínculo menos forte, tanto com o trabalho quanto com a organização (neste caso, além de menores, o comprometimento instrumental é superior ao afetivo), diferenciando-se bastante dos trabalhadores administrativos. Trata-se de um resultado que reproduz, em contexto diverso, a clássica diferença entre trabalhadores de atividades meio e fim.

Os resultados obtidos, como se pode constatar, confirmam algumas tendências (relação da idade, do tempo de serviço e da centralidade do trabalho com o comprometimento) e algumas das indefinições (relação do gênero e da escolaridade com o comprometimento) existentes na literatura produzida sobre comprometimento do trabalhador inserido em organizações privadas industriais, de serviço e no setor público. O quadro revela também algumas especificidades (por exemplo, a associação do comprometimento com a norma social de obediência) que são base para análises adicionais dos dados já disponíveis e para novas pesquisas que aprofundem a compreensão do fenômeno estudado naquele segmento e contexto de trabalho.

Vale ressaltar que lidar com esse novo segmento de trabalhadores teve como implicação positiva a necessidade de ajustar ferramentas já validadas para o estudo do comprometimento, reafirmando a importância da adequação dos instrumentos e procedimentos ao universo linguístico e cultural dos participantes.

Produzidos a partir de um projeto de grande porte, os dados aqui apresentados, em um nível descritivo, deverão ser objeto de análises estatísticas multivariadas, ampliando o escopo da compreensão dos fatores determinantes do comprometimento do trabalhador e do impacto desse comprometimento sobre o desempenho organizacional. 


\section{Referências}

ALBUQUERQUE, F.J.B. Psicologia social e formas de vida rural no Brasil. Psicologia: Teoria e Pesquisa, v. 18, n. 1, p. 37-42, jan./abr. 2002.

BAIARDI, A. Neoprodutivismo, neoassociativismo e turismo campestre: outras faces do novo rural. Caderno CRH, Salvador, n. 28, p. 11-25, 1998.

BASTOS, A.V.B. Comprometimento no trabalho: a estrutura dos vínculos do trabalhador com a organização, a carreira e o sindicato. Tese de Doutorado. Universidade de Brasília, 1994.

Comprometimento no trabalho: o estado da arte e uma possível agenda de pesquisa. Cadernos de Psicologia, n. 1, p. 4463, 1995.

Comprometimento no trabalho: contextos em mudança e os rumos da pesquisa deste domínio. Anais da ENANPAD. Foz do Iguaçu, PR (cd-rom), 1998.

BASTOS, A.V.B. e COSTA, F.M. Múltiplos comprometimentos no trabalho: articulando diferentes estratégias de pesquisa. Anais da ENANPAD. Florianópolis - SC (cd-rom), 2000.

BECKER, T. Foci and Bases of commitment: are they distinctions worth making? Academy of Management Journal, v. 35, n. 1, p. 232-244, 1992.

BECKER, T.E.; BILLINGS, R.J. Profiles of commitment: an empirical test. Journal of Organizational Behaviorl, v. 14, n. 2, p. 177190, 1993.

BORGES-ANDRADE, J.E.; AFANASIEFF, R.S.; SILVA, M.S. Mensuração de comprometimento organizacional em instituições públicas. Ribeirão Preto: Sociedade de Psicologia de Ribeirão Preto, 1989. p. 236.

BRANCO, A.M.; VAINSENCHER, S.A. Gênero e globalização no Vale do São Francisco. Recife/ Fundação Joaquim Nabuco: Revista Ciência \& Trópico, 2001.
CARVALHO, B.C.T. Terceirização e comprometimento no trabalho: um estudo de caso na COELBA. 2000. 202 f. Dissertação (Mestrado em Administração Estratégica), Universidade Federal da Bahia, Salvador, 2000.

COHEN, A. Multiple commitments in workplaces: an integrative approach. Mahwah, New Jersey: Lawrence Erlbaum Associates, 2003. COOPER-HAKIM, A.; VISWESVARAN C. The construct of work commitment: testing an integrative framework. Psychological Bulletin, v. 131, n. 2, p. 241-259, 2005.

DEMO, G. Comprometimento no trabalho: uma síntese do estado da arte e uma revisão da produção nacional. Psicologia: Organizações e Trabalho, v. 3, n.2, p. 185-231, 2003.

DIAS, D.S.; MARQUES, A.L. Múltiplos comprometimentos: um estudo com profissionais e gerentes de uma grande empresa do setor metal-mecânico. In: ENANPAD, 2002, Salvador. Anais... Salvador, 2002, cd-rom.

DUFUMIER, M.; COUTO, V. A. Neoprodutivismo. Caderno CRH, Salvador, $\mathrm{n}$. 28, p. 81-111, 1998.

FAVERO, C. A. A globalização e as novas experiências dos agricultores. Caderno CRH, Salvador, n. 28, p. 27-57, 1998.

FINK, S.L. High commitment workplaces. New York: Quorum Books, 1992.

FISCHER, I.R. A trabalhadora rural: conscientização política e social na empresa agrícola moderna. Recife: FUNDAJ; Massangana, 2000.

FOSSÁ, M.I.T.; SARTORETTO, P.M. Responsabilidade social empresarial e comprometimento organizacional: uma relação possível? In: ENANPAD, 2002, Salvador. Anais... Salvador, 2002, cd-rom.

FRANÇA, F.M.C.; PEREIRA NETO, A.; MEIRA, J.N. Documento referencial do polo de desenvolvimento integrado Petrolina/Juazeiro. Banco do Nordeste. Disponível em: <http:// www.bnb.gov.br/content/aplicacao/etene/rede_ irrigacao/Docs/Documento\% 20Referencial\%20 
do\%20Polo\%20Juazeiro-Petrolina.PDF>. Acesso em: 09 nov. 2004, (199-).

GUERREIRO, F. Fruticultura irrigada na Bahia. Cadernos de Análise Regional - Economia Baiana, ano IV, número especial, p. 117-138, 2003.

GUERREIRO, L.F.; MATTA, J.P.R.; MACÊDO, W. Agroindústria na Bahia: diagnóstico e perspectivas da cadeia produtiva. Estudo Setorial 03/02 agosto. Agência de Fomento do Estado da Bahia - Desenbahia, 2002.

LIMA, J.P.R.; MIRANDA, E.A.A. Fruticultura irrigada no Vale do São Francisco: incorporação tecnológica, competitividade e sustentabilidade. In: ENCONTRO REGIONAL DE ESTUDOS DO TRABALHO (ABET), 3., 2000, Recife. Anais... Recife, 2000, cd-rom.

MATHIEU, J.; ZAJAC, D. A review and metaanalysis of the antecedents, correlates, and cosequences of organizational commitment. Psychological Bulletin, v.108, n.2, p.171-194, 1990.

MEDEIROS, C.F.M.; ALBUQUERQUE, L.G.; MARQUES, G.M. Comprometimento e desempenho organizacional: um estudo da estrutura de relacionamentos dos componentes do comprometimento com o desempenho das empresas hoteleiras. In: ENANPAD, 2004, Curitiba. Anais... Curitiba, 2004, cd-rom.

MEDEIROS, C.A.F. et al. Comprometimento organizacional: o estado da arte da pesquisa no Brasil. In: ENANPAD, 2002, Salvador. Anais... Salvador, 2002, cd-rom.

MEDEIROS, C.A.F.; ENDERS, W.T. Validação do modelo de conceitualização de três componentes do comprometimento organizacional de Meyer e Allen: um estudo dos padrões de comprometimento organizacional e suas relações com a performance no trabalho. In: ENANPAD, 1997, Rio das Pedras. Anais... Rio das Pedras, 1997, cd-rom.

MEDEIROS, C.A.F.; ENDERS, W.T. Padrões de comprometimento organizacional e suas características pessoais: como são os comprometidos e os descomprometidos com as organizações In: ENANPAD, 1998, Foz do Iguaçu. Anais... Foz do Iguaçu, 1998, cd-rom. MEDEIROS, C.A.F. et al. Três (ou quatro?) componentes do comprometimento organizacional. In: ENANPAD, 1999, Foz do Iguaçu. Anais... Foz do Iguaçu, 1999, cd-rom. MEYER, J.P.; ALLEN, N.J. Commitment in the workplace: theory, research and application. Thousands Oaks: SAGE, 1997.

MEYER, J. P. et al. Affective, continuance, and normative commitment to the organization: a meta-analysis of antecedents, correlates, and consequences. Journal of Vocational Behavior, v. 61, p. 20-52, 2002.

MORAES, L.F.R. et al. Comprometimento organizacional: um estudo de caso comparativo em universidades federais mineiras. In: ENANPAD, 1997, Rio das Pedras. Anais... Rio das Pedras, 1997, cd-rom.

MORROW, P.C. The theory and measurement of work commitment. Greenwich, CT: Jai, 1993.

MOW. International Research Team. The meaning of working. London: Academic Press, 1987.

MOWDAY, R.T.; STEERS, R.M.; PORTER, L.W. The measurement of organizational commitment. Journal of Vocational Behavior, n. 14, p. 224247, 1979.

MOWDAY, R.T.; PORTER, L.W.; STEERS, R.M. Employee-organization linkages: the psychology of commitment, absenteeism, and turnover. New York: Academic Press, 1982.

NAVARRO, Z. From historical obstacles to new routes of rural development. In: WINROCK INTERNATIONAL (Org.). Rural poverty in the Northeast of Brazil: a participatory study. Salvador: Winrock International, FIB - Faculdade Integrada da Bahia, 2000. p. 49-68.

\section{SCHEIBLE, A.C.F. Comprometimento no}

trabalho: um estudo de caso de suas relações com desempenho e práticas de gestão. 2004. 180f. Dissertação (Mestrado Profissionalizante em Administração) - Programa de Pós- 
Graduação em Administração, Universidade Federal da Bahia, Salvador, 2004.

SEl. Superintendência de Estudos Econômicos e Sociais da Bahia. Especialização da agricultura e organização do espaço agrícola no Estado da Bahia. Salvador: Série Estudos e Pesquisas, n. 54, p. 7-38, 2001.

\section{Avaliação do PRONAF crédito na}

Bahia. Salvador: SEl, 2002. . Recentes transformações no rural

baiano. Salvador: Série Estudos e Pesquisas, $n$. 68, p. 5-68, 2003.

SIQUEIRA, M.M.M. Comprometimento organizacional afetivo, calculativo e normativo: evidências acerca da validade discriminante de três medidas brasileiras. In: ENANPAD, 2001, Campinas. Anais... Campinas, 2001, cd-rom.

SIQUEIRA, M.M.M.; GOMIDE JÚNIOR, S. Vínculos do indivíduo com a organização e com o trabalho. In: ZANELLI, J.C.; BORGESANDRADE, J.E.; BASTOS, A.V.B. (Orgs.).

Psicologia, organizações e trabalho. Porto Alegre: Artmed, 2004. p. 300-328.

TAMAYO, A. et al. Relação entre os valores do empregado e o comprometimento organizacional afetivo. In: ENANPAD, 2000, Florianópolis. Anais... Florianópolis, 2000, cdrom.

TAMAYO, A. et al. Prioridades axiológicas e comprometimento organizacional. Psicologia: Teoria e Pesquisa, v. 17, n. 1, p. 027-035, 2001.

WITTE, H.D.; NÄSWALL, K. 'Objective' vs 'subjective' job insecurity: consequences of temporary work for job satisfaction and organizational commitment in Four European countries. Economic and Industrial Democracy, v. 24, n. 2, p. 149-188, 2003. 